\title{
Practical Deliberation and Background Conditions on Normative REAsons FOR ACtion
}

\author{
RACHEL A. JOHNSON \\ Trinity University
}

This paper concerns accounts of normative reasons for action that distinguish between the content of a reason and its "background conditions" (the explanation of why it is a reason). Such accounts sometimes appeal to this distinction to try to avoid what I will call "problematic thought objections". These objections reject some accounts of normative reasons because (they claim) those accounts allow agents to have thoughts or motivations that a well-functioning practical reasoner ought not or cannot have (e.g., thoughts about her desires). These "problematic thoughts" concern the targeted account's explanation of why reasons are reasons, so accounts that distinguish between reasons and background conditions can attempt to avoid these objections by claiming that thoughts about background conditions are not part of practical deliberation. I argue that this response fails because it is possible for a well-functioning practical reasoner's motivation by a normative reason to include a recognition of its background conditions even if the reason itself does not. A wellfunctioning practical reasoner's motivation by a normative reason may include motivation by the recognition that her reason (at least partially) justifies her action. This recognition may include an understanding of the background conditions on reasons. If this is right, it suggests a constraint on accounts of normative reasons: an account must be such that a practical reasoner can be moved by thought about its explanation of the nature of normative reasons without thereby becoming less well-functioning.

ormative reasons for action are considerations that count in favor of ac-
tions (at least for particular agents, under particular circumstances). ${ }^{1}$ They are the considerations that determine what an agent should do in a given

1. This description of a normative reason for action comes from T. M. Scanlon (1998: 17), but is now widely used.

Contact: Rachel Johnson <rjohnso8@trinity.edu> 
situation. If the agent acts on these considerations, they (at least partially) justify her action. ${ }^{2}$ This paper concerns accounts of normative reasons that separate the explanation of why a particular reason counts in favor of an agent's performing some action (in a particular set of circumstances) from the content of that reason. Elements of this explanation of why the reason is a reason are "background conditions" on that reason, rather than part of (or referenced in) the reason itself. ${ }^{3}$

Accounts of normative reasons that distinguish between reasons and their background conditions sometimes appeal to this distinction to avoid objections of a particular general kind. These objections - which I will call "problematic thought objections"-employ the following line of thought to reject some accounts of normative reasons: According to the proposed account of normative reasons, a well-functioning practical reasoner engaged in practical deliberation will (or at least may) have some thought or motivation that, according to the objector, a well-functioning practical reasoner ought not or cannot have. These problematic thoughts concern elements of the (proposed) explanation of what makes considerations count in favor of actions. Thus, we should reject the proposed account of normative reasons because it fails to accurately characterize excellent practical deliberation.

Accounts of normative reasons that distinguish between reasons and their background conditions sometimes claim to avoid problematic thought objections as follows: Practical deliberation consists in considering and being moved by reasons for action. The (supposedly) problematic thoughts concern the explanation of why reasons are reasons (the background conditions on reasons), not reasons themselves. Thus, these problematic thoughts will not appear in an agent's practical deliberation and will not themselves move her to act.

In what follows, I aim to show that this appeal to background conditions does not allow an account of normative reasons to avoid this form of objection. I will argue that, even if normative reasons contain no reference to the background conditions that make them reasons, it is possible for a well-functioning practical reasoner's motivation by those reasons to contain a recognition of these background conditions. ${ }^{4}$ I will argue that recognizing these background conditions

2. "At least partially" is meant to take into account the fact that a normative reason for an agent $\mathrm{A}$ to perform some action $\phi$ in circumstances $\mathrm{C}$ may not be sufficient to justify A's $\phi$-ing in $C$. A reason "justifies" an action by doing more than showing that action to be permissible, but often does less than show that action to be required. Roughly, a reason (partially) justifies an action by showing that it is a worthwhile thing to do (other things equal). 37).

3. The term "background condition" (used in this way) comes from Mark Schroeder (2007:

4. My aim in this paper is not to support what Schroeder (2007: 23-24, 34-37) calls the "No Background Conditions" view - the view that all elements of the explanation of why a reason is a reason are part of this reason - and attributes to John Broome, Thomas Nagel, and Joseph Raz (see also Broome 2004; Nagel 1970; Raz 1999). I am sympathetic to the distinction between reasons and 
can be part of an agent's recognition of normative reasons as normative reasons. At least some well-functioning practical reasoners are moved by this recognition that their reasons are normative as well as by those reasons themselves. Thus, appealing to a distinction between reasons and background conditions does not provide a way to remove thought about background conditions from all wellfunctioning practical deliberation so as to avoid problematic thought objections. The failure of this kind of response to problematic thought objections suggests a constraint on accounts of normative reasons for action: well-functioning practical reasoners must be able to be moved by thought about the correct account of normative reasons when engaged in practical deliberation without thereby becoming less well-functioning.

To make this argument, I will frequently use, as an example, Mark Schroeder's (2007) appeal to background conditions to avoid a common objection to Humean accounts of reasons (that such accounts require agents to be moved by thoughts about what will satisfy their own desires when deciding what to do). However, the problem I will raise for Schroeder's use of background conditions to avoid this particular problematic thought objection does not depend on his particular view about what the background conditions on reasons are. (Nor does it depend on the particular form that this objection subsequently takes - that the "problematic thought" is morally suspect thought about one's desires.) As a result, the problem I raise should apply to any view that separates the explanation of why reasons count in favor of actions from the content of those reasons and then appeals to this distinction to keep otherwise problematic thoughts out of practical deliberation. I will briefly discuss other problematic thought objections at the end of Section 2. I will briefly discuss other appeals to background conditions to avoid these objections at the end of Section 3 .

\section{Background Conditions on Normative Reasons for Action}

An account of normative reasons gives an explanation of why a consideration $(\mathrm{R})$ counts in favor of an agent (A) performing some action $(\phi)$. An account of normative reasons that distinguishes between background conditions and the reasons they explain claims that $\mathrm{R}\left(\mathrm{A}^{\prime} \mathrm{s}\right.$ reason to $\left.\phi\right)$ contains no reference to the facts that together explain why $R$ is a reason for $A$ to $\phi$. These facts are instead background conditions on A's reason to $\phi$. For example, Schroeder's account of normative reasons for action is Humean-it uses an agent's desires to explain

background conditions itself because I think it fits well with our ordinary discourse concerning normative reasons. 
what makes a consideration count in favor of her $\phi$-ing. ${ }^{5}$ Schroeder (2007: 59) claims that a consideration $\mathrm{R}$ is a reason for an agent $\mathrm{A}$ to perform a particular action $\phi$ when and because $R$ is part of an explanation of why A's $\phi$-ing would promote the satisfaction of one (or more) of A's desires. (An action promotes the satisfaction of a desire when it increases the likelihood that the desire will be satisfied relative to a baseline of doing nothing; 2007: 113.) Nevertheless, an agent's reasons are usually ordinary facts about the world like "there will be dancing at the party" rather than facts about the agent's desires like "the agent desires to dance" (2007: 27). An agent's reasons contain no references to the desires that make them reasons. Facts about these desires and what promotes their satisfaction are instead "background conditions" on these reasons (2007: 37).

\section{Problematic Thought Objections}

Problematic thought objections to accounts of normative reasons for action are objections that take the following form: The targeted account of normative reasons identifies some facts that explain why a consideration is a normative reason (i.e., facts that make a consideration count in favor of an agent's performing some action). For simplicity, I will call these facts "facts of kind B". A well-functioning practical reasoner will (or at least may) consider and be moved by facts of kind $\mathrm{B}$ when engaged in (excellent) practical reasoning. However, given what kind of facts these facts of kind B are, it would be in some way objectionable or problematic for agents to consider and be moved by them when deliberating about what to do. If we assume that an account of normative reasons should be consistent with an accurate description of how well-functioning practical reasoners reason, then we must conclude that it cannot be facts of kind B that explain reasons.

For example, a common objection to Humean accounts of normative reasons is that they make correct practical reasoning "objectionably self-regarding" (Schroeder 2007: 25). Because a Humean theory of reasons makes an agent's reasons depend on her desires, such a theory would seem to require agents to have and be moved by thoughts about their own desires (and what would promote their satisfaction) when deciding what to do. However, we might think that, at least in some cases, a well-functioning practical reasoner will not have and be moved by such thoughts about her own desires. For example, if an agent is considering whether to help a drowning man, we might think that, ideally, she will think about him and what he needs, rather than about herself and what she

5. This characterization of a "Humean" account of reasons for action is common, but not universal. For example, according to Kate Manne's (2016) “Humean" account, an agent's reasons can be explained by other people's desires (as well as by that agent's desires). Such an account will not be subject to the objection to Humean accounts of reasons explained in Section 2. 
wants, when deciding what to do. ${ }^{6}$ Furthermore, we might think that something like this is true of all cases in which agents respond to reasons stemming from the moral standing of others. We might think that, when we do our duty with respect to others, we should be moved by a concern for their rights or wellbeing rather than by thought about what would satisfy our own desires.7 There is something objectionably self-centered about an agent who takes the rights or well-being of others to make claims on her only because of their relation to her desires. ${ }^{8}$

The "problematic thoughts" that the objectionably self-regarding objection identifies are problematic because they are morally non-ideal or indicative of a flawed character. However, thoughts can be "problematic" in other ways when they appear in practical deliberation. Constructivist accounts of normative reasons seem to give rise to a different kind of problematic thought objection. Put very roughly, constructivist accounts of normative reasons for action claim that agents make considerations count in favor of actions by choosing ends. These choices create normative reasons only if they are made in accordance with certain norms that are supposed to be constitutive of practical reasoning, but these norms do not fully determine the ends that an agent should choose. An agent's reasons then pick out features of her actions or their expected outcomes that help explain how these actions will serve one (or more) of the agent's properly chosen ends (see, e.g., Korsgaard 1996a; 1996b; and Street 2008).

We might worry that, if an agent reflects on the fact that it is her contingent choices (and nothing about the chosen ends themselves) that make these (purportedly) reason-giving features of actions count in favor of those actions, this

6. In describing this agent as "ideal", I aim to remain neutral on the question of how exactly the agent who is moved by thoughts about her own desires is falling short (e.g., whether she acts wrongly, whether she exhibits some character flaw, or whether altruistic motivation is to be praised though its absence is not to be criticized).

7. In order to act, an agent must have some motivation (or desire) to act. What is (purportedly) objectionable in these cases is not the motivation (or desire) to act, but rather taking one's desires into account when deciding what to do. As Philip Pettit and Michael Smith (1990) point out, having and acting from a desire does not require taking it into account in one's practical deliberation.

8. There are at least two ways of understanding the charge that Humean practical reasoning is objectionably self-regarding. The first is that (at least in some cases) it would be objectionably self-centered of an agent to have and be moved by thoughts about her own desires and what would promote their satisfaction when deciding what to do. (This, I think, roughly corresponds to what Schroeder, 2007: 37-38, calls the "Wrong Place objection".) Second, the charge that Humean practical reasoning is objectionably self-regarding could be understood as claiming just that Humean theories of reasons cannot account for the possibility of altruistic motivation (that is not flawed or enthymematic). Thomas Nagel (1970: 80) expresses such a concern in The Possibility of Altruism. Schroeder calls it the "Self-Regarding objection" (2007: 25-26). I think that these two objections express interrelated concerns that are best understood together. (The concern driving the "Wrong Place objection" provides a reason for thinking that altruistic motivation is not flawed or enthymematic.) 
would make it difficult for the agent to regard these features of her action as normative. To put the point rather crudely, it would be difficult for this agent to regard these features of actions as making genuine demands on her once she recognizes that she could have chosen (and in some cases can still choose) other ends without error (and thus have different reasons). So, thought about the constructivist explanation of why reasons are reasons seems potentially problematic if it appears in practical deliberation, but this is not because such thought is morally objectionable. Such thought is problematic because it undermines an agent's ability to see her normative reasons as normative. 9

Furthermore, problematic thought objections need not only be directed at desire-based accounts of reasons. Perhaps the most familiar problematic thought objections are variants of Williams's (1981) "one thought too many" objection. Briefly, Williams claimed that there is something wrong with an agent who impartially considers the question of whether to save the life of his wife or that of a stranger. This objection targets all impartialist moral theories, not just those that ground moral reasons in something like desires (e.g., preference utilitarianism).

My aim in this paper is not to defend any particular problematic thought objection. Thus, I am not defending the claim that considering one's desires when deciding whether to do one's duty with respect to others is objectionably self-

9. Contemporary uses of "the open question argument" to reject naturalistic accounts of normative reasons can also be understood as problematic thought objections in which thought about the proposed explanation of normative reasons is problematic because it undermines the agent's ability to see her reasons as normative (see, e.g., Rosati 2003).

David Enoch's (2006) "shmagency" objection to constitutivist accounts of practical normativity (of which constructivism is one kind) can also be understood as a problematic thought objection of this kind. Constitutivist accounts of practical normativity claim that which normative reasons an agent has is determined by standards or aims that are constitutive of agency. Enoch claims that such accounts fail to fully account for practical normativity because they cannot explain why an agent should accept the standards or aims that are constitutive of agency (and thus be an agent) rather than accept some other set of standards or aims (and thus be a "shmagent"). This objection becomes a problematic thought objection if it is made from the perspective of the agent: Without an answer to the question "why should I be an agent?", a practical reasoner would have difficulty seeing the standards or aims that are constitutive of agency as making any real claims on her (as genuinely normative).

While this formulation of the shmagency objection looks very similar to the objection to constructivism described above, these objections have importantly different targets. The shmagency objection claims that no matter which standards or aims we propose as constitutive of agency, thought about the constitutive nature of these standards or aims will be problematic because an agent will need a reason to accept these standards or aims in order to see them (and the reasons to which they give rise) as normative. On the other hand, the objection to constructivism described above claims that the particular standards or aims that constructivists propose as constitutive of practical reasoning bring an element of arbitrariness into an agent's reasons that undermines an agent's ability to see her reasons as normative. This problem is with the particular standards or aims that constructivists propose as constitutive of practical reasoning. Thus, a satisfactory reply to the shmagency objection would not necessarily constitute a satisfactory reply to this objection to constructivism. 
regarding, the claim that an agent would be unable to see her reasons as normative if she understood their constructivist origins, or the claim that one ought not to impartially consider the question of whether to save one's intimates or strangers. (Each of these claims requires independent support if the problematic thought objection of which it is a part is to be persuasive.) Instead, I aim to defend a presupposition that underlies this form of objection-the idea that a well-functioning practical reasoner may have and be moved by thoughts about what makes her reasons count in favor of actions. If this presupposition is true, it places a constraint on accounts of normative reasons for action: a plausible account of normative reasons for action must be such that an agent can be moved by thought about its explanation of normative reasons while deliberating about what to do without thereby becoming less well-functioning.

\section{Using Background Conditions to Avoid Problematic Thought Objections}

Problematic thought objections suppose that an agent will consider and be moved by the facts that explain why her reasons are reasons. Accounts of normative reasons that take these facts to be background conditions on reasons can attempt to deny this. For example, Schroeder (2007: 37) claims that his view does not make practical reasoning objectionably self-regarding because only an agent's reasons appear in her practical deliberation. Because desires are background conditions on reasons, an agent's desires explain why her reasons are her reasons, determine what reasons she has, and thus determine what she ought to do. However, none of this requires that the agent deliberate about her desires when deciding what to do. She need only consider and be moved by her reasons themselves. Thus, when an agent decides to save a drowning man, she can have the thoughts "he needs help" and "so I will help him". She need not think "and I want to help him" to arrive at this decision.

Constructivists can make a similar move in order to avoid the concern that, if an agent recognizes that her reasons are grounded in her own contingent choices, she will have difficulty regarding these reasons as normative. Suppose that practical deliberation involves making normative judgments (e.g., judgments about normative reasons like " $R$ is a reason for $A$ to $\phi$ in circumstances $X, Y$, $\mathrm{Z}$..."), assessing and revising these judgments, and coming to a decision about what one will do on the basis of these judgments. Reflection on the constructivist origins of one's reasons does not fit into any of these categories. Although we might have thought that such reflection could be part of the process of assessing and revising normative judgments, constructivists can deny this. For example, according to Sharon Street's (2008: 223) characterization of a constructivist ac- 
count of normative reasons, an agent assesses a judgment about reasons by determining whether it "withstands scrutiny from the "standpoint of [her] other judgments about reasons". This means that the agent assesses and revises her judgments about reasons using her other normative judgments (and the norms that are constitutive of practical reasoning ${ }^{10}$ ) as standards. The agent does not assess and revise these judgments on the basis of thought about their constructivist origins. Only other normative judgments provide grounds for rejecting a normative judgment. Thus, thought about the constructivist origins of normative reasons would seem to have no place in practical deliberation. ${ }^{11}$

Something like an appeal to background conditions is also often made in response to "one thought too many" objections. A number of impartialists about morality have proposed "indirect" or "two level" theories of moral motivation to address at least some interpretations of the "one thought too many" objection. For example, "indirect" or "two level" consequentialists claim (roughly) that well-functioning practical reasoners need not always directly consider the (impartial) question of what will maximize the good when engaged in practical deliberation. These agents can have reasons to pursue certain ends, activities or relationships for their own sakes even though these reasons are still in some way explained by the ultimate end of maximizing the good (see, e.g., Mason 1999; and Railton 1984).

10. According to Street (2008), the norms that are constitutive of practical reasoning are quite minimal consistency norms, so an agent need do nothing more than assess her normative judgments against each other in order to assess them against these norms. According to Korsgaard (1996a; 1996b), the norm that is constitutive of practical reasoning (the categorical imperative) is more substantive, so an agent could assess her normative judgments against this norm as well as against her other normative judgments.

11. There are two ways of understanding the constructivist's reply: (1) Thought about the constructivist origins of normative reasons would undermine an agent's ability to see her reasons as normative if it did appear in her practical deliberation, but such thought is not actually part of practical deliberation. (2) Thought about the constructivist origins of normative reasons is not the right sort of thought to undermine a judgment that something is a normative reason. (I) has the same form as Schroeder's appeal to background conditions, but (2) does not. (2) resembles Matthew Silverstein's response to Enoch's shmagency objection. Silverstein claims that "There are no standpoints outside of agency where questions about one's reasons are apt (or even intelligible). And thus there are no normative questions about agency or shmagency left unanswered by agency's constitutive norm" (2015: 1141). Perhaps this reply to the shmagency objection succeeds in defending the correct constitutivist account of normative reasons (whatever it is). But even if so, (2) does not seem to me to be a plausible defense of constructivism. This is because it is pretty clear that arbitrariness does undermine normative judgments for actual agents. (Michael Smith, 1997: 90, goes so far as to say "the only decisive point we can make about normativity is that arbitrariness, as such, always undermines normativity.") An account that claims otherwise fails as a constitutivist account of our actual practices involving normative reasons. 


\section{Refining Problematic Thought Objections and the Appeal to Background Conditions Response}

At first glance, there seems to be a straightforward problem for this way of attempting to avoid problematic thought objections: The background conditions on an agent's reasons explain why she has those reasons (and not others). (For example, according to Schroeder's view, different agents have different reasons when and because they have different desires.) As a result, it would seem that an agent would need to reflect on the background conditions on her reasons in order to reliably get it right about what reasons she has. Thus, thought about the background conditions on normative reasons would seem to have a place in a well-functioning practical reasoner's practical deliberation. In this section, I will discuss how background conditions theorists may be able to avoid this objection. In doing so, I will make clearer the precise form of problematic thought objection that I aim to defend in Section 5 .

Background conditions theorists are not without resources to explain how an agent could identify her reasons without reflecting on (or even being aware of) the background conditions that make those considerations reasons. For example, in a constructivist view, agents would identify normative reasons by relying on other normative judgments (Street 2008). An agent could have a coherent set of normative judgments that provides support for each of her (correct) reason-takings without knowing why this set of coherent normative judgments is correct while other possible coherent sets are not (i.e., without knowing that this is the set of reasons that arise from the permissible aims to which she has committed herself). Schroeder, on the other hand, suggests that agents identify their reasons through a perception-like process.

Roughly, according to Schroeder (2007: 156-157), when an agent has a desire for $\mathrm{P}$, she is disposed to find salient considerations that (given the agent's beliefs) obviously help explain why performing certain actions would promote $\mathrm{P}$ and these "salience-strikings" tend to prompt the agent to perform these actions. Schroeder claims that this close connection between an agent's salience-strikings and her actual reasons suggests that these salience-strikings have the content that the relevant considerations are reasons even if the agent has not reflected on the desires that make these considerations reasons (2007: 159). Similarly, an agent's perceptual experiences may have the content that there is something red in front of her even if she has not reflected on the facts about light waves and her perceptual system that make it the case that the object in front of her is red and explain this perception (2007: 160-162).

While I think it reasonable to be skeptical that agents could reliably identify their reasons, even in hard cases, without reflecting on the explanation of what makes them reasons, this paper will not attempt to show that this is im- 
possible. Instead I will suppose that it is possible for agents to reliably identify their reasons without reflecting on their background conditions and argue that background conditions theorists are still unable to avoid an important variety of problematic thought objections. Problematic thought objections are often understood as relying on the presupposition that thought about the explanation of why one's reasons are reasons must appear in a well-functioning practical reasoner's practical deliberation. If background conditions theorists can successfully explain why thought about background conditions is never necessary to identify the right reasons on which to act, then they will have undermined the most obvious way of supporting this presupposition. However, problematic thought objections can also be understood to rely on the weaker claim that it is possible for a well-functioning practical reasoner to think about the explanation of why her reasons are reasons when she decides what to do. If reflection about the background conditions on reasons is never necessary to reliably identify the right reasons, it seems that a well-functioning practical reasoner may still engage in it. ${ }^{12}$ Even if we are capable of identifying our reasons without understanding what makes them reasons, presumably part of the point of seeking an account of normative reasons is to give us additional resources for identifying the non-obvious reasons we have. Furthermore, even if it turns out that the correct account of normative reasons is of no practical help in identifying reasons, it is hard to see what could be objectionable or non-ideal about an agent contemplating the (correct) explanation of why she has the reasons she has. ${ }^{13}$ Reflection on the truth about reasons should not in itself make an agent a less than ideal practical reasoner. (I will provide additional support for this claim in Section 5.)

A background conditions theorist could try to accept this claim (and avoid any corresponding problematic thought objections) by appealing to a commonly drawn distinction between practical deliberation with reasons and theoretical reflection about the grounds of one's reasons. Practical deliberation culminates in an agent forming intentions to act. When engaged in practical deliberation, an agent takes considerations to be reasons. A reason-taking is not simply a judgment that a consideration is a reason. It also motivates the agent to act (or would motivate the agent to act, other things equal). By contrast, an agent's thoughts about why she has these reasons do not directly move her to do (or intend to do) anything. The theoretical reflection in which such thoughts appear results in the formation of beliefs about what reasons the agent has (and why) rather than in intentions and actions. (If those beliefs then result in reason-takings, which in

12. Alex Gregory (2009: 252) also makes this point.

13. There may be cases in which extensive reflection on what reasons one has and why would impede efficiently complying with one's reasons. However, it is unlikely that extensive reflection is inappropriate in all cases in which, e.g., considering the desires that (allegedly) ground one's reasons seems non-ideal. 
turn lead to action, it is the reason-takings and not the thoughts about why these reasons are reasons that move the agent to act. $)^{14}$

This distinction between practical reasoning with normative reasons and theoretical reasoning about normative reasons seems to provide a way for a well-functioning practical reasoner to consider the explanation of why she has the reasons she has when deciding what to do while avoiding any problematic thought objections that explanation might provoke. This solution supposes that it is only practical deliberation that needs to be free of problematic thoughts. Such thoughts (e.g., thought about one's desires) are objectionable or problematic only when they are motivating. An ideal practical reasoner may have these thoughts when deciding what to do as long as they appear only in her theoretical reasoning about why she has the reasons she has and not in the considerations that move her to act. ${ }^{15}$

\section{Vindicating Problematic Thought Objections: Thought about Background Conditions Remains in Practical Deliberation}

Nonetheless, I aim to show that an appeal to background conditions is not an adequate response to a problematic thought objection. The background conditions theorist may be right that the explanation of why a reason counts in favor of an action is not part of that reason itself. The background conditions theorist may also be right that it is possible for a well-functioning practical reasoner to identify her reasons without reflecting on (or even knowing about) the background conditions that make them reasons. And finally, the background conditions theorist may be right that practical deliberation consists solely of reasons-takings. If so, however, I think that it is possible for a well-functioning practical reasoner's reason-taking to consist of more than her being moved by a thought about the content of a reason. A well-functioning practical reasoner can also be moved by the recognition that her reason justifies her action. And this, I will argue, prevents neatly relegating thoughts about background conditions out of practical deliberation in order to avoid problematic thought objections.

14. Constructivists can be understood as appealing to this distinction (see Footnote 11). Schroeder initially describes the distinction as that between thinking about normative reasons and thinking about the explanatory reasons that make them normative reasons (2007: 37). He later describes the salience-strikings that involve seeing considerations as reasons as tending to prompt action (2007: 159). The recognition that some of the agent's desires explain these salience-strikings (and the corresponding reasons) need not be motivating since this recognition is unnecessary for an agent to act for a reason.

15. Note that background conditions theorists could use this same strategy to try to avoid problematic thought objections if reflection on the background conditions on reasons does turn out to be necessary in order to reliably identify one's reasons. 
The argument to follow will make use of two main claims. The first is:

Reasons Motivation: It is possible for a well-functioning practical reasoner to be moved to act by both

a. the normative reasons that in fact apply to her in the relevant circumstances and

b. the recognition that these considerations are normative reasons (that they make her action appropriate or justified in the relevant circumstances).

Reasons Motivation is a weakened version of the widely accepted idea that there is, at least in principle, a difference between acting for a normative reason and acting on a mere desire, impulse or compulsion. ${ }^{16}$ Often, when an agent acts, she takes the consideration that moves her to act to be a normative reason. She is not merely moved to act by a consideration that may happen to be normative-a consideration that may happen to count in favor of her action. She is moved to act in part by some recognition that this consideration is normative. She is moved to act in part by some recognition that her reason makes her action appropriate or (at least partially) justified under the circumstances.

A stronger claim than Reasons Motivation - the claim that a practical reasoner must be moved to act by (b) as well as (a) in order to count as wellfunctioning - is widely accepted (even among background conditions theorists and despite significant disagreement about what makes a consideration a normative reason; see, e.g., Raz 2010; Scanlon 1998; Schroeder 2007; Street 2008; and Velleman 2000). I find this stronger claim plausible, but the argument to follow requires only the weaker Reasons Motivation. Reasons Motivation claims that one way of being a well-functioning practical reasoner involves being moved to act by (b) as well as (a). An agent does not become less well-functioning just because she is moved to act by the recognition that the considerations for which she acts justify her actions (as well as by those considerations themselves).

16. While this distinction is widely accepted in principle, it is a matter of some debate whether there are actual cases in which agents act on mere desires without acting for reasons that they take to be normative. Korsgaard's (2008: 50) example of a Civil War soldier who resists having his leg amputated even though he knows that this is necessary to save his life and Kieren Setiya's (2010: 90-92) example of a person fleeing a burning building and leaving his family inside are potential examples of people acting on mere desires rather than for reasons that they take to be normative. Cases of choosing between equally good options or between incommensurate goods on a whim or "because I feel like it" are also sometimes proposed as instances of acting on mere desire. (For a discussion of such cases, see Chang 2004.) 
I think that Reasons Motivation is fairly uncontroversial. ${ }^{17}$ Nevertheless, I will provide a brief defense of it here. This defense relies on the idea that good practical reasoning can be an accomplishment. It is something that agents can permissibly strive for and for which they can deserve praise or credit of a particular kind. I will argue that, to be credited with the accomplishment of good practical reasoning, a well-functioning practical reasoner must be motivated by a recognition that her reasons justify her actions.

I will suppose that there is some notion of accomplishment such that if something is an accomplishment for an agent, then the agent must have been trying to do it well (or at least better than she might). She must have some (at least rudimentary) awareness of the standards that apply to that type of activity and see herself as regulating her activity according to these standards. She must see herself as doing what she is doing because she takes it to be appropriate or correct. When she succeeds, her activity meets those standards on purpose. For this to be the case, it is not enough that there is some mechanism within the agent that makes her comply with these standards. She must see herself as guiding her activity using the standards. ${ }^{18}$

So, how does this apply to practical reasoning? There are at least two possible accomplishments in practical reasoning: doing the right thing (or, in many cases, doing one of multiple worthwhile options) and acting for the right reasons (i.e., being moved to act by considerations that do in fact count in favor of that action). If the agent were merely moved to act by the right considerations and not also by any recognition that they are normative reasons (that they justify her actions), then there would be nothing that she did that would count as using the standards that determine which are the right reasons to guide her practical

17. One way of understanding "one thought too many" objections makes them objections to Reasons Motivation. Such an objection would claim that thought about anything other than the content of a reason is one thought too many. (I.e., an ideal agent is moved solely by a thought about the content of a reason and by no recognition that it is a reason.) I find this objection difficult to motivate. While some suggest that being moved by the (actual) right-making features of actions is sufficient for well-functioning practical reasoning (see, e.g., Arpaly 2002), this does not imply that a well-functioning practical reasoner must be so moved (or that the mere recognition that a consideration is a good reason on which to act is itself one thought too many). There may be some special cases in which this recognition is non-ideal. (Perhaps Williams's case of a man deciding whether to save his wife or a stranger is one of these special cases.) If so, however, I think that the correct analysis of such cases is that they are cases in which an ideal person would temporarily abandon practical reasoning. They should not be understood as paradigmatic cases of excellent practical reasoning around which to build a theory of normative reasons.

18. While I think that the description just given fits our ordinary use of "accomplishment", it should not matter for the argument below that this is so. I will use "accomplishment" as shorthand for the activity just described-doing something well on purpose out of a recognition of what it is to do that kind of thing well. (Note that this notion of accomplishment differs in an important respect from Gwen Bradford's, 2015, notion of "achievement": achievements are difficult, but accomplishments need not be.) 
deliberation. She could not see herself as acting on these considerations (rather than others) because she takes doing so to be appropriate or correct. If so, perhaps doing the right thing would count as her accomplishment (because she uses the reasons that make her action appropriate or correct to guide her behavior), but acting for the right reasons would not.

I think it tempting to suppose that the best practical reasoners achieve all possible accomplishments of practical reasoning. However, even if this is not so (i.e., even if a practical reasoner who is to be credited only with doing the right thing is beyond reproach), it seems likely that one way of being a well-functioning practical reasoner involves both accomplishments. In earning credit for the "extra" accomplishment of acting for the right reasons, a practical reasoner assumes greater knowledge of and control over her practical reasoning than the reasoner who is to be credited only with doing the right thing. The agent who acts for the right reason without the recognition that these reasons justify her actions knows at most that she does the right thing and thus this is all that she does well on purpose. The agent who is moved to act in part by the recognition that her reasons justify her actions also knows that she acts for the right reasons and thus does something else well on purpose. If a practical reasoner continues to do the right thing, it is hard to see how this greater knowledge of and control over what she is doing could be objectionable in itself. One cannot become a worse practical reasoner simply by acting for the right reasons on purpose out of a recognition that they are the right reasons. ${ }^{19}$

This idea that it is possible for a well-functioning practical reasoner to be motivated by the recognition that her reasons justify her actions undermines the background conditions theorist's claim that a well-functioning practical reasoner's practical deliberation contains no thought about background conditions when it is combined with:

Reasons Recognition: It is possible for a well-functioning practical reasoner's recognition that considerations justify actions (i.e., her recognition of normative reasons as normative reasons) to include an understanding of what makes a consideration count in favor of an action.

19. Zoë A. Johnson King (2018) and Paulina Sliwa (2016) argue that, for an action to have moral worth, it must be right non-accidentally, and that for an action to be right non-accidentally, the agent must be moved by some recognition or knowledge that her action is the right thing to do. If (as seems plausible) recognition that one's action is the right thing to do involves recognition that one's reasons justify one's actions, these arguments seem to support a stronger version of Reasons Motivation (one in which motivation by the recognition that one's reasons justify one's actions is necessary for ideal practical reasoning). I am sympathetic to Johnson King and Sliwa's view of moral worth, but the argument of this paper does not require that it is correct. While I have appealed to similar ideas about complying with standards of correctness on purpose in my defense of Reasons Motivation, I do not mean to claim that the "accomplishments" of practical reasoning described above are necessary or sufficient for an action to have moral worth. 
To see why we should accept Reasons Recognition, first note that an account of normative reasons' explanation of what makes a consideration count in favor of an action provides a substantive conception of justification by a normative reason-it tells us what it is for a consideration to provide justification for an action. For example, according to Schroeder's view, a consideration that is a normative reason for an agent to $\phi$ does not, by itself, make $\phi$-ing appropriate or (at least partially) justified. A consideration does this insofar as it is part of an explanation of how $\phi$-ing promotes the satisfaction of one (or more) of the agent's desires. Furthermore, Schroeder's (2007: 79-83) account of reasons (like many contemporary accounts) is intended to give a constitutive explanation of what he takes to be the basic normative concept (a reason). Because of this, he could accept no conception of practical justification that did not have to do with what promotes the satisfaction of the agent's desires.

As stated in Section 4, I think there is good reason to be skeptical that an agent can reliably recognize the right reasons as the right reasons without using some substantive conception of justification (of the kind that an account of what makes considerations count in favor of actions provides) to apply to potential reasons. However, for the sake of argument, I have supposed that this is possible. Perhaps an agent is able to identify normative reasons by relying on other normative judgments, even though she lacks the deeper understanding of the nature of practical justification that an account of normative reasons aims to provide. Or perhaps Schroeder is right that agents are able to identify reasons through a perception-like process. Either way, if an agent lacks a substantive conception of justification by a normative reason, the conception of "reason" or "justifies" that this agent employs when she recognizes normative reasons as normative reasons must be rather thin (i.e., something like "makes the action appropriate under the circumstances").

An agent who identifies her normative reasons in these ways cannot count acting for the right reasons among her accomplishments in quite the same sense that her doing the right thing may count among her accomplishments. In my defense of Reasons Motivation, I suggested that there is some notion of accomplishment such that for something count as accomplishment for an agent, she must see herself as doing what she is doing because she takes it to be appropriate or correct. She must have some awareness of the standards that apply to the type of activity she is engaged in and see herself as regulating her activity according to these standards. In the case of the accomplishment of doing the right thing, it is common to think of a well-functioning practical reasoner as moved by more than a bare sense that her action is appropriate or correct. She is also moved by the particular considerations that make the action an appropriate or correct thing to do (her normative reasons). She is not moved simply by a thin conception of the appropriateness of her action, but is also moved by some sub- 
stantive understanding (provided by her reasons) of the standards that make her action appropriate or correct. Reasons Recognition claims something similar about acting for the right reasons - that a well-functioning practical reasoner can be moved to select the reasons on which to act not just by a bare notion that they make her action appropriate or justified but instead by a recognition of the substantive explanation of what makes a reason (at least partially) justify an action (and why it applies in this case).

But why think that well-functioning practical reasoners can be moved by a substantive conception of correctness when selecting the reasons on which to act as well as when selecting which actions to perform? One could accept Reasons Motivation without accepting this stronger claim. For example, Schroeder's account of reason-takings as (a particular kind of) salience-strikings allows him to say that a well-functioning practical reasoner's practical deliberation is guided by the background conditions that determine her reasons because (likely unbeknownst to her) these background conditions also explain her salience-strikings (2007: 156-157). What he denies is that this practical reasoner experiences herself as regulating her reason selections using an understanding of what makes considerations count in favor of actions. Roughly, certain considerations seem to her to make actions appropriate and, under normal conditions, justify belief that they do make actions appropriate, just as certain objects seem to her to be red and, under normal conditions justify belief that they are red (2007: 174).

I will argue that at least one category of possible well-functioning practical reasoners must be moved by an understanding of a substantive conception of justification when identifying reasons-well-functioning practical reasoners who know the correct account of normative reasons. Suppose that a practical reasoner understands the correct theory of normative reasons - she understands what makes a consideration count in favor of an action. Suppose that it is possible for well-functioning practical reasoners to reliably identify their reasons without using this theory. Suppose that Reasons Motivation is true and this practical reasoner is among those who are moved to act by the recognition that her reason justifies her action as well as by the reason itself. For this person's practical deliberation to remain free of thought about what makes a consideration count in favor of an action, her recognition that her reason justifies her action (her recognition that it is a reason) must be free of her understanding of what makes a consideration count in favor of an action.

This seems implausible because, in explaining what makes considerations count in favor of actions, accounts of normative reasons give an account of what justification by a normative reason is. They give an account of what it is for a consideration to be a genuine normative reason and this just is (at least a large part of) what it is for a reason to contribute to the justification of an action. This is particularly clear in an account like Schroeder's (2007: 61-62) because he explic- 
itly claims to be giving a constitutive account or reduction of the normative with respect to action, but any account of what makes a consideration count in favor of actions is a conception of what practical reasoning and justification by normative (practical) reasons are. A Humean view that grounds an agent's normative reasons in her own desires takes the basic way in which reasons justify actions to be by showing that those actions will help agents get what they want. Practical justification, according to this view, is something quite different from what it is, for example, according to a view in which reasons are grounded in some specific substantive values(s) or according to a view in which reasons are created by an agent's autonomous choices in accordance with some formal norms.

If an agent understands that water is $\mathrm{H}_{2} \mathrm{O}$, then there is no significant distinction between her recognition that something is water and her recognition that it is $\mathrm{H}_{2} \mathrm{O}$. The same is true for justification by a normative reason. If an agent has an understanding of what makes considerations count in favor of actions (an understanding of what justification by a normative reason is), then there should be no significant distinction between her recognition that a consideration (at least partially) justifies her action and her recognition of what it is for this consideration to (at least partially) justify her action..$^{20}$

At this point, it should be easy to see why it is possible for thought about background conditions to appear in the practical deliberation of at least some well-functioning practical reasoners who understand the nature of normative reasons: When such an agent acts for a reason, while the consideration that moves her to act (the reason) may contain no reference to the background conditions that make it a reason, her complete motivation for acting may contain such a reference. The content of her motivation may be more than just the content of the consideration that moves her. She may also be motivated by her recognition that her reason provides some justification for her action and she understands

20. I suspect that many ordinary practical reasoners are also moved by some substantive (though likely flawed and incomplete) conception of justification when they act for reasons out of a recognition that those considerations justify their actions. Plausible accounts of normative reasons generally contain a core idea of what makes a consideration a normative reason that is familiar - a reason shows that an action will get the agent what she wants, a reason shows that an action will help the agent achieve an end to which she has committed herself and which determines who she is, a reason shows that an action will bring about some good, etc. Most accounts accept that there is some truth to all of these descriptions of a reason. I think this suggests that many of us are not operating with the thin conception of justification described above when engaged in practical deliberation, but instead seek, acquire, and use an understanding of the substantive standards that determine the right reasons on which to act.

A plausible (and complete) account of normative reasons should be able to explain how it is that "ordinary" good reasoners are moved by a partial or incomplete understanding of the correct account of normative reasons. This might place constraints on what the correct account of normative reasons can be. (See, e.g., Star 2011 for an attempt to give such an explanation that is not neutral between different accounts of normative reasons.) 
what this justification by a normative reason is. For any view that proposes background conditions on reasons to explain when and why considerations count in favor of actions, those background conditions determine what constitutes justification by a normative reason. What it is for a consideration to justify an action is (at least in part) for background conditions of this kind to hold. Therefore,

Background Conditions in Practical Deliberation: It is possible for a well-functioning practical reasoner to be moved to act in part by some recognition of the background conditions that make a consideration a normative reason when she acts for that reason.

Thus, the distinction between reasons and background conditions does not remove thought about these background conditions from all well-functioning practical reasoners' practical deliberation. If these background conditions give rise to problematic thought objections, then appealing to a distinction between reasons and background conditions will not circumvent these objections. ${ }^{21}$

For example, suppose Schroeder is correct that reasons justify actions by being part of the explanation of how those actions promote one or more of the agent's desires. An agent who knows this and is moved to act by the recognition that her reasons justify her actions, as well as by those reasons themselves, is moved by the recognition that her reasons call for so acting because they show how those actions will promote one or more of her desires. If this agent is moved by the recognition that someone needs help, she is also moved by the recognition that the fact that this person needs help counts in favor of the agent's helping him because helping him will promote one or more of her desires. Thus, this agent takes the well-being of this other person to make claims on her because of its relationship to her desires and remains objectionably self-regarding in just the way described in Section 2.

The failure of this kind of response to problematic thought objections suggests a constraint on accounts of normative reasons for action. An explanation of

21. To be fair, it is not immediately clear how to apply this line of thought to the "two level" theories of moral motivation proposed as responses to one thought too many objections. This is because there is debate about what exactly is objectionable about thought about impartiality in practical deliberation in one thought too many cases. For example, we might think it objectionable (a) that the agent have this thought at all, (b) that she have this thought without having some other thoughts (e.g., about her personal relationships) or (c) that her thoughts about impartiality play a particular role in her practical deliberation (e.g., that they move her to act directly). If one thought too many objections claim (a) (see, e.g., Wolf 2012), and if the argument of Section 5 is correct, then two level accounts of moral motivation will not avoid such objections. However, two level accounts may successfully address one thought too many objections understood as claiming (b) or (c) because neither clearly require ruling thought about impartiality out of practical deliberation altogether in one thought too many cases. 
what makes a consideration count in favor of an action must be such that a wellfunctioning practical reasoner can be moved by thought about its explanation of the nature of normative reasons when deliberating about what to do without thereby becoming less well-functioning (i.e., without having problematic attitudes). Problematic thought objections presuppose such a constraint. The basic reason why appeals to background conditions fail to avoid these objections (i.e., that motivation by a reason may contain motivation by some recognition of what makes reasons count in favor of actions) supports this constraint. If this is right, then if we are to reject a particular problematic thought objection, we must do so by showing that thought about the particular proposed explanation of what makes a consideration a reason in question is not problematic when it appears in practical deliberation. We cannot avoid these objections by claiming that well-functioning practical reasoners will not have thoughts about this explanation at all.

\section{Acknowledgements}

I owe thanks to many people for helpful conversations and feedback about the ideas in this paper including Stephen Finlay, Camil Golub, Barbara Herman, Pamela Hieronymi, Brian Hutler, Zoë Johnson King, Ting Cho Lau, Gavin Lawrence, Alexander Patsaouras, Tamar Weber, Stephen White, and audiences at the 2017 St. Louis Annual Conference on Reasons and Rationality, the 2017 Central Division meeting of the American Philosophical Association and the 2016 Iowa Philosophical Society Conference. I would also especially like to thank Mark Schroeder and an anonymous referee for Ergo whose feedback helped me significantly improve the paper. Much of the work on this paper was made possible by a pre-tenure academic leave from Trinity University.

\section{References}

Arpaly, Nomy (2002). Moral Worth. The Journal of Philosophy, 99(5), 223-245. https://doi. org/10.2307/3655647

Bradford, Gwen (2015). Achievement. Oxford University Press. https://doi.org/10.1093/ac prof:0so/9780198714026.001.0001

Broome, John (2004). Reasons. In R. Jay Wallace, Philip Pettit, Samuel Scheffler, and Michael Smith (Eds.), Reason and Value: Themes from the Moral Philosophy of Joseph Raz (28-55). Oxford University Press.

Chang, Ruth (2004). Can Desires Provide Reasons for Action? In R. Jay Wallace, Philip Pettit, Samuel Scheffler, and Michael Smith (Eds.), Reason and Value: Themes from the Moral Philosophy of Joseph Raz (56-90). Oxford University Press. 
Enoch, David (2006). Agency, Shmagency: Why Normativity Won't Come from What Is Constitutive of Action. Philosophical Review, 115(2), 169-198. https://doi. org/10.1215/00318108-2005-014

Gregory, Alex (2009). Slaves of the Passions? On Schroeder's New Humeanism. Ratio, 22(2), 250-257. https://doi.org/10.1111/j.1467-9329.2009.00429.x

Johnson King, Zoë A. (2018). Accidentally Doing the Right Thing. Philosophy and Phenomenological Research. Advance online publication. https://dx.doi.org/10.1111/ phpr.12535

Korsgaard, Christine M. (1996a). The Reasons We Can Share: An Attack on the Distinction between Agent-Relative and Agent-Neutral Values. In Creating the Kingdom of Ends (275-310). Cambridge University Press.

Korsgaard, Christine M. (1996b). The Sources of Normativity. Cambridge University Press. https://doi.org/10.1017/CBO9780511554476

Korsgaard, Christine M. (2008). The Normativity of Instrumental Reason. In The Constitution of Agency: Essays on Practical Reason and Moral Psychology (27-68). Oxford University Press. https://doi.org/10.1093/acprof:0so/9780199552733.003.0002

Manne, Kate (2016). Democratizing Humeanism. In Errol Lord and Barry Maguire (Eds.), Weighing Reasons (123-140). Oxford University Press. https://doi.org/10.1093/acprof: oso/9780199315192.003.0006

Mason, Elinor (1999). Do Consequentialists Have One Thought Too Many? Ethical Theory and Moral Practice, 2(3), 243-261. https://doi.org/10.1023/A:1009998927955

Nagel, Thomas (1970). The Possibility of Altruism. Princeton University Press.

Pettit, Philip and Michael Smith (1990). Backgrounding Desire. The Philosophical Review, 99(4), 565-592. https://doi.org/10.2307/2185617

Railton, Peter (1984). Alienation, Consequentialism, and the Demands of Morality. Philosophy E Public Affairs, 13(2), 134-171.

Raz, Joseph (1999). Engaging Reason: On the Theory of Value and Action. Oxford University Press.

Raz, Joseph (2010). On the Guise of the Good. In Sergio Tenenbaum (Ed), Desire, Practical Reason, and the Good (111-137). Oxford University Press. https://doi.org/10.1093/acpr of:0so/9780195382440.003.0006

Rosati, Connie S. (2003). Agency and the Open Question Argument. Ethics, 113(3), 490527. https://doi.org/10.1086/345625

Scanlon, T. M. (1998). What We Owe to Each Other. The Belknap Press of Harvard University Press.

Schroeder, Mark (2007). Slaves of the Passions. Oxford University Press. https://doi. org/10.1093/acprof:0so/9780199299508.001.0001

Setiya, Kieran (2010). Sympathy for the Devil. In Sergio Tenenbaum (Ed), Desire, Practical Reason, and the Good (82-110). Oxford University Press. https://doi.org/10.1093/acpro f:0so/9780195382440.003.0005

Silverstein, Matthew (2015). The Shmagency Question. Philosophical Studies, 172(5), 11271142. https://doi.org/10.1007/s11098-014-0340-x

Sliwa, Paulina (2016). Moral Worth and Moral Knowledge. Philosophy and Phenomenological Research 93(2), 393-418. https://doi.org/10.1111/phpr.12195

Smith, Michael (1997). In Defense of "The Moral Problem": A Reply to Brink, Copp, and Sayre-McCord. Ethics, 108(1), 84-119. https://doi.org/10.1086/233789 
Star, Daniel (2011). Two Levels of Moral Thinking. Oxford Studies in Normative Ethics, 1, 75-96. https://doi.org/10.1093/acprof:0so/9780199693269.003.0004

Street, Sharon (2008). Constructivism about Reasons. In Russ Shafer-Landau (Ed.), Oxford Studies in Metaethics (Vol. 3, 207-245). Oxford University Press.

Velleman, J. David (2000). The Possibility of Practical Reason. Oxford University Press.

Williams, Bernard (1981). Persons, Character, and Morality. In Moral Luck: Philosophical Papers 1973-1980, (1-19). Cambridge University Press.

Wolf, Susan (2012). 'One Thought Too Many': Love, Morality, and the Ordering of Commitment. In Ulrike Heuer \& Gerald Lang (Eds.), Luck, Value and Commitment: Themes from the Ethics of Bernard Williams (71-94). Oxford University Press. 